SFB

Liquidity premia and interest

823

rate parity

Ludger Linnemann, Andreas Schabert

Nr. 43/2013
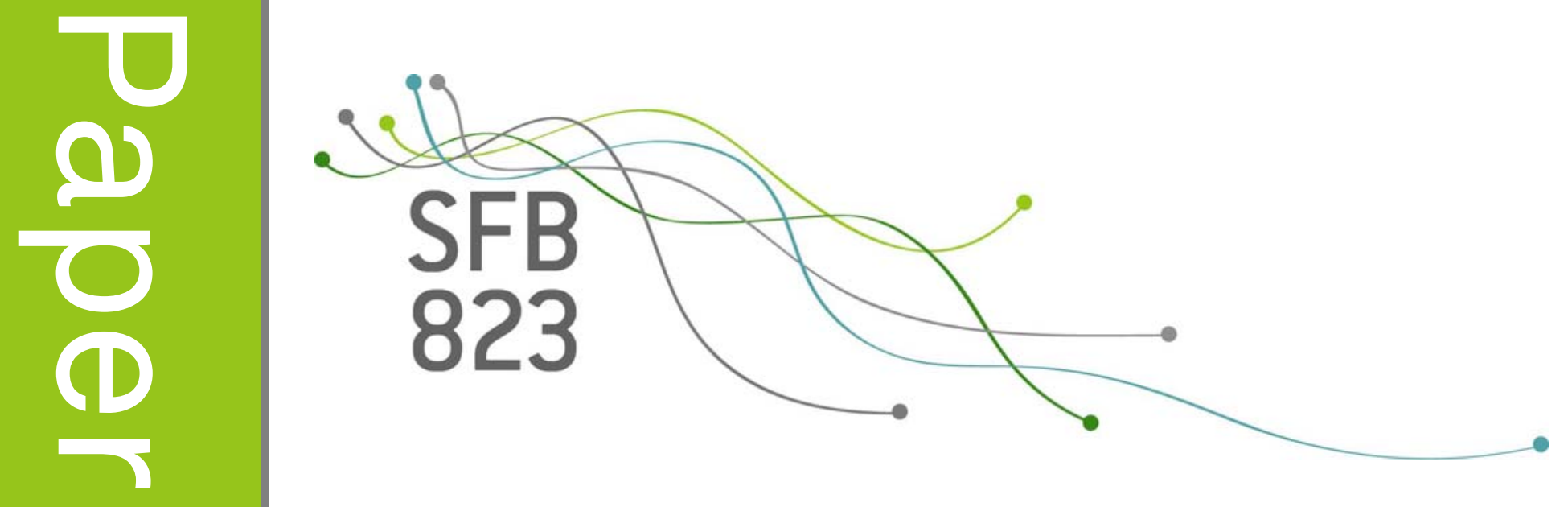



\title{
Liquidity Premia and Interest Rate Parity ${ }^{1}$
}

\author{
Ludger Linnemann \\ TU Dortmund University \\ Andreas Schabert ${ }^{2}$ \\ University of Cologne
}

This version: October 29, 2013

\begin{abstract}
Risk-free assets denominated in US currency not only offer a pecuniary return, but also provide transactions services, both nationally and internationally. Accordingly, the responses of bilateral US dollar exchange rates to interest rate shocks should differ substantially with respect to the (US or foreign) origin of the shock. We demonstrate this empirically and apply a model of liquidity premia on US treasuries originating from monetary policy implementation. The liquidity premium leads to a modification of uncovered interest rate parity (UIP), which is able to explain observed deviations of exchange rate dynamics from UIP predictions. In line with empirical evidence, the model predicts an appreciation of the US dollar subsequent to an increase in US interest rates as well as in SOE interest rates.
\end{abstract}

JEL classification: E4; F31; F41.

Keywords: Exchange rate dynamics, uncovered interest rate parity, monetary policy shocks, liquidity premia.

\footnotetext{
${ }^{1}$ The authors would like to thank Klaus Adam, Giancarlo Corsetti, Ben Craig, Mathias Hoffmann, and Michael Krause for helpful comments and suggestions. Financial support from the Deutsche Forschungsgemeinschaft (SFB 823) is gratefully acknowledged.

${ }^{2}$ Corresponding author: Andreas Schabert, University of Cologne, Center of Macroeconomic Research, AlbertusMagnus-Platz, 50923 Cologne, Germany, Phone: +49 0172267 4482, Email: schabert@wiso.uni-koeln.de.
} 


\section{Introduction}

We study the role of liquidity premia on assets for exchange rate responses to changes in monetary policy rates. Our starting point consists of two observations. First, standard open economy macro models typically involve a version of uncovered interest rate parity (UIP), which states that the expected rate of depreciation is equal to the differential between home and foreign short-term interest rates. However, it is well established that this theoretical prediction is rarely confirmed by empirical data (see Froot and Thaler, 1992, or Engel, 2013, for surveys on the evidence). Second, returns on certain types of assets can be affected by the existence of liquidity premia. At least short-term treasuries arguably help to facilitate market transactions, for example through their use as collateral, and the liquidity services these assets provide are non-pecuniary benefits that are reflected in their price (see e.g. Longstaff, 2004, or Krishnamurthy and Vissing-Jorgensen, 2012).

The point we make in this paper results from combining these two observations. Specifically, we argue that the failure of the UIP prediction, i.e. the observed lack of association between interest rate differentials and expected depreciation rates, may be partly due to movements in endogenous liquidity premia. We present a macroeconomic approach to modelling a liquidity premium on treasuries, which originates from monetary policy implementation, and show that its endogenous movements can contribute to explaining observed deviations from UIP predictions. In particular, endogenous liquidity premia give a reason why a currency appreciates for a prolonged time span subsequent to an increase in the domestic interest rate. To see this, note that when the domestic monetary policy rate increases, the price of money in terms of the collateral required in open market operations (typically treasury securities) also increases, such that the liquidity premium on treasuries falls. With rational investors, arbitrage freeness leads to a modified UIP condition that takes into account both the pecuniary and the non-pecuniary (i.e. the liquidity service) components of the total returns on treasuries. It implies that an observed increase in home interest rates and the resulting international interest rate differential overstates the impact on the exchange rate, given that part of the interest rate increase is off-set by the endogenous change in the liquidity premium. Indeed, we show that when foreign interest rates show a moderately positive association with home interest rates (a property that is borne out empirically), the effect of a monetary policy induced home interest rate increase may well be a subsequent appreciation instead of a depreciation.

The association of a home interest rate increase with a subsequent exchange rate appreciation is precisely what has been found by a number of empirical studies. Most notably, Eichenbaum and Evans (1995) have presented VAR evidence pointing out that a contractionary U.S. monetary policy shock leads the dollar to appreciate for many periods, until it peaks after around three years, which they explain as delayed overshooting. More recently, Scholl and Uhlig (2008) reconfirm the result and find that the exchange rate peaks between 17 and 26 months after a monetary shock. These findings are in contrast to UIP predictions, and as such have proven difficult to 
explain (see Engel, 2013). Our approach to account for transaction services of treasuries leads to an endogenous liquidity premium that can contribute to explaining the observed exchange rate reactions to changes in interest rates differentials. We show that - when we account for the observed degree of co-movement between interest rates - the model can rationalize an expected appreciation following a home interest rate increase, much as found in the empirical studies quoted above. ${ }^{3}$ We demonstrate that the endogenous liquidity premium can help explaining the impulse response of the exchange rate with respect to monetary policy shocks, though it cannot fully solve the puzzling finding that regressions of depreciation rates on interest rate differentials (as performed e.g. by Fama, 1984, and surveyed in Froot an Thaler, 1992) notoriously tend to find coefficients much smaller than the value of one that is predicted by UIP, and sometimes even find negative coefficients.

The model we use is an open economy version of the one in Reynard and Schabert (2013), where the liquidity premium is shown to behave according to Krishnamurthy and Vissing-Jorgensen's (2012) evidence and to be able to explain the observed systematic spread between (real) monetary policy rates and the marginal rate of intertemporal substitution (see Canzoneri et al. 2007 and Atkeson and Kehoe 2009). While several theoretical approaches have emphasized that assets other than money may be valued for their transactions services (see e.g. Bansal and Coleman, 1996, Canzoneri et al., 2008, Linnemann and Schabert, 2010), the precise way in which assets provide liquidity is left open. In contrast, the approach by Reynard and Schabert (2013) explicitly derives the liquidity value of treasuries from the property that they are eligible in open market operations, and can thus be transformed into central bank money at a cost which is given by the policy rate. As an implication, returns on treasuries and on non-eligible assets differ by an endogenous liquidity premium that varies with the stance of monetary policy. We embed this in a model of the US viewed as a large open economy that interacts with the rest of the world consisting of small open economies. We recognize the fact that its currency has a special role in the international payments system, in that large parts of trade are conducted in US dollar, which has been labelled as key currency pricing by Canzoneri et al. (2013a). ${ }^{4}$ Since assets that give access to US currency are therefore particularly valuable for their holders in comparison to assets denoted in other currencies that are less important in international trade, it follows that changes in US interest rates are predicted to have different consequences than changes in interest rates of any small open economy.

We assess the empirical validity of this implication of our model by means of a panel vector autoregression with monthly data from the US and a number of small open economies. We find that - in line with earlier empirical evidence - an increase in the US monetary policy rate leads to

\footnotetext{
${ }^{3}$ In related literature, it has been noted that there may be other ways in which modelling the liquidity value of bonds may help with international empirical puzzles, such as exchange rate volatility puzzle or the Backus-Smith puzzle, as demonstrated by Canzoneri et al. (2013a).

${ }^{4}$ Canzoneri et al. (2013a) analyze costs and benefits of the particular status of the US dollar. Hoermann and Schabert (2012) examine the impact of key currency pricing on exchange rate dynamics in a two-country model.
} 
a prolonged period of appreciation. ${ }^{5}$ This violation of the UIP prediction is compatible with our model if the small open economy interest rate responds moderately positively to a US interest rate increase. We show that this is fulfilled empirically, since the average small open economy interest rate has a peak response of slightly less than one half of the peak increase of the US rate (while there is no comparable reaction of US rates to interest rate shocks in small open economies). Further, a monetary tightening through an interest rate increase in the average small open economy triggers a response of bilateral exchange rates with respect to the dollar that is qualitatively more in line with the UIP prediction, in that it produces an almost immediate increase in the depreciation rate of the small open economy currency with respect to the dollar. The empirical finding that there is hardly any deviation from UIP predictions when considering small open economies (whose currencies are not prominent in international trade) is compatible with Bjornland (2009), who confirmed that depreciation of the small open economy currency follows an domestic interest rate increases for Australia, Canada, New Zealand and Sweden. In the context of our model, it is possible to explain both an appreciation of the US dollar subsequent to increases in the US monetary policy rate and in non-US interest rates. The reason is that an increase in the US policy rate (i.e. the Federal Funds Rate) raises the rate on US treasuries and involves a reduction in their liquidity premium, which is a special property of assets giving access to US currency. According to our model, the liquidity premium together with the empirically observed positive international linkage of nominal policy interest rates is able to account for the US dollar appreciation following an increase in US interest rates relative to foreign interest rates.

The rest of the paper is organized as follows. Section 2 presents empirical evidence supporting the view that bilateral exchange rates between the US dollar and the currencies of small open economies deviate from the prediction of UIP when US monetary policy shocks are considered, while UIP is not rejected for interest rate shocks originating from small open economies. Section 3 presents the model, whereupon section 4 analytically derives the main result for a simplified model version. The quantitative properties of a parameterized version of the model are discussed in section 5; section 6 concludes.

\section{Empirical evidence}

In this section, we present empirical evidence on asymmetries in the exchange rate responses to monetary policy shocks of different origins, which are suggestive of the role of liquidity premia on US assets in explaining deviations from UIP. In particular, we follow Eichenbaum and Evans (1995) and estimate VAR models to assess the impact of monetary policy shocks on exchange rates. In contrast to previous studies that either focus on US monetary policy shocks or on interest rate differentials

\footnotetext{
${ }^{5}$ Engel (2012) and Canzoneri et al. (2013b) also discuss how transaction services of bonds can contribute to international empirical puzzles. They model liquidity of bonds in an implicit way, which tend to lead to a positive sign rather than the observed negative sign for the correlation between the rate of depreciation and the interest rate differential.
} 
(see Eichenbaum and Evans, 1995, Scholl and Uhlig, 2008), we distinguish between shocks to US monetary policy and shocks to monetary policy in a number of small open economies (SOE henceforth) for which comparable data are available. We show that, using recursively identified VARs with monthly data, as already emphasized in previous literature (Eichenbaum and Evans, 1995, Scholl and Uhlig, 2008) there is a pronounced and prolonged appreciation subsequent to a US policy rate shock. However, we find that this behavior of exchange rates is much less pronounced in response to a shock to the monetary policy rate of SOEs. The latter finding is similar to the results reported by Bjornland (2009) in her study of four small open economies (Australia, Canada, New Zealand, Sweden). Our findings suggest that these results could be explained by the special role of US assets and the liquidity value that they provide to their holders. Specifically, we find an unexpected increase in the US short-run nominal interest rate to be followed by several months of a decreasing US dollar exchange rate (hence an appreciation), while an unexpected increase to money market interest rates in small open economies that do not share the US's special role in international finance leads to a more immediate appreciation of the SOE currency followed by depreciation, consistent with UIP. We interpret this evidence as suggestive for the property of US assets that are valued for their liquidity services by domestic investors as well as by international investors; the latter accounting for the specific role of the US dollar as a key currency for international transactions.

We use monthly data to estimate a panel VAR model capturing the average bilateral interaction between the US and a number of SOEs (listed below). The VAR is estimated in the vector of variables $Z_{t}=\left[x_{t}^{U S}, \pi_{t}^{U S}, R_{t}^{m, U S}, R_{t}^{U S}, x_{t}^{i}, \pi_{t}^{i}, R_{t}^{i}, S_{t}^{i}\right]^{\prime}$. The superscript $U S$ denotes US variables, whereas the superscript $i$ refers to one out of the group of small open economies for which all data are available at monthly frequency. The variable $x_{t}$ is the growth rate of industrial production, $\pi_{t}$ is the CPI inflation rate, $R_{t}^{m, U S}$ is the short-run nominal policy interest rate, taken to be the Federal Funds Rate for the US, $R_{t}^{U S}$ is the US three months treasury bill rate, whereas $R_{t}^{i}$ is the interest rate on three months treasury securities for the $\mathrm{SOEs}^{6}$, and $S_{t}^{i}$ is the $\log$ of the nominal bilateral exchange rate between the $i$-th country and the US dollar (denoted such that a decrease indicates a nominal appreciation). A monetary policy shock is an innovation to the orthogonalized residual of the nominal interest rate equation. Identification is achieved similarly to Eichenbaum and Evans (1995) by assuming a contemporaneous recursive ordering where the variables are ordered as given in the definition of $Z_{t}$. This entails the assumption that US monetary policy can react contemporaneously to innovations in US production growth and inflation, but interest rate shocks affect the former two variables only after a lag of at least one month. Likewise, the central bank of the $i$-th small open economy is able to react to innovations in both domestic and US production and inflation, while there is a one month lag before interest rate

\footnotetext{
${ }^{6}$ Due to limited data availability, for three out of the ten countries considered below (Denmark, Finland, and the Netherlands), we had to use the IMF's measure of overnight interest rates instead.
} 
shocks affect these. The nominal exchange rate, being ordered last, can react contemporaneously to all shocks. Furthermore, by ordering US variables first, it is assumed that US variables are affected only with at least a one month lag to shocks in the small open economy, whereas the latter's variables all respond immediately to US shocks. The results, however, not dependent on the recursive identification assumption. Bjornland (2009) uses a long-run restriction approach for the identification of monetary shocks (in quarterly data, where the recursiveness assumption is more critical) by imposing a zero long-run effect of monetary policy on the real exchange rate. The results are similar when using her approach. ${ }^{7}$

Monthly data on seasonally adjusted industrial production, consumer price indices, the overnight nominal interest rate and the bilateral exchange rate with respect to the US dollar are obtained from the IMF International Financial Statistics database. The group of small open economies consists of Belgium, Canada, Denmark, Finland, France, Germany, Italy, the Netherlands, and Sweden. The data series mostly begin in 1975m1 except for Finland, where data availability starts in $1977 \mathrm{~m} 12$, Germany, where it starts in $1975 \mathrm{~m} 5$, and Italy, where it starts in $1977 \mathrm{~m} 2$. For the countries that joined the Euro area in 1999, the series end in 1998m12, whereas for the remaining countries the data end in $2008 \mathrm{~m} 12$. We determine the lag length using the Schwarz information criterion. For all two country pairs, this criterion suggests either using one or two lags. We consequently use a two lag specification for the VAR, though we checked that using only one or up to six lags would not lead to different conclusions. Furthermore, entering the price level and industrial production variables in log-levels, instead of growth rates, produces very similar results.

We estimate the model in the form of a non-balanced panel VAR with country fixed effects (as in Ravn, Schmitt-Grohe and Uribe, 2012, the sample size is large enough to allow us to neglect the possible source of bias from correlation between fixed effect and regressors as identified by Nickell, 1981). Also, we checked that estimating individual two country VARs and averaging the results instead of using a panel approach lead to very similar conclusions. We compute the impulse responses of the nominal exchange rate with respect to an orthogonalized positive one unit shock to the US nominal policy interest rate $R_{t}^{m, U S}$ (indicating a monetary policy shock in the US) and with respect to an orthogonalized positive one unit shock to the nominal interest rate $R_{t}^{i}$ (indicating a monetary policy shock in the average SOE). In figure 1 , we show two sets of impulse responses, along with bootstrapped two standard deviation bands, namely in each row those of the US treasury rate $R_{t}^{U S}$, the SOE treasury rate $R_{t}^{i}$, and the bilateral exchange rate $S_{t}^{i}$. The first row of panels shows responses to a unit shock to the US nominal policy interest rate, and the second row of panels those to a shock to the SOE interest rate. For better readability, in the figure the exchange rate responses are presented from the point of view of the country in

\footnotetext{
${ }^{7}$ Thus, while Bjornland (2009) interprets the difference between her results and those of Eichenbaum and Evans (1995) and related studies as a result of differences in the identification strategy, our results suggest that the difference is rather due to the asymmetry between US and SOE interest rate shocks that our model seeks to explain.
} 

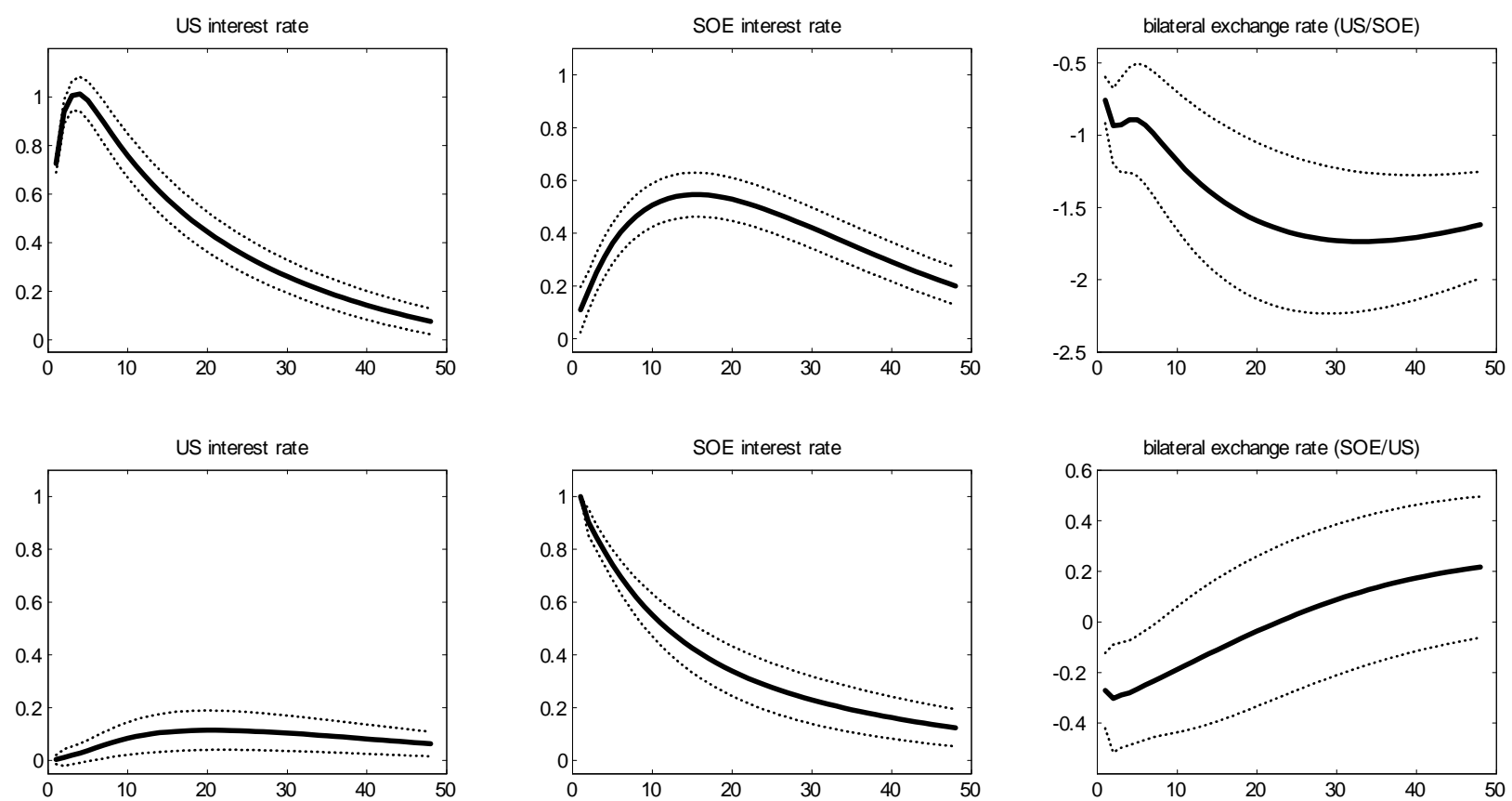

Figure 1: Impulse responses to US monetary policy shock (first row) and to SOE monetary policy shock (second row).

which the monetary policy shock occurs. Thus, a decrease of the exchange rate following a US monetary policy shock (upper right panel) means an appreciation of the US dollar with respect to the small open economy's exchange rate, whereas a decrease of the exchange rate following a SOE monetary policy shock (lower right panel) means an appreciation of the small economy's exchange rate vis-a-vis the US dollar.

The upper row of panels in figure 1 displays a result that is well known from previous studies: in response to a US monetary tightening, the US treasury rate $R_{t}^{U S}$ that is shown in the upper left panel increases persistently, and the US dollar appreciates (relatively to the SOE currencies in the sample) with a pronounced hump-shaped pattern with a peak response that occurs almost 30 months after the shock (upper right panel). This continuing appreciation for around two years after an interest rate increase is a clear violation of uncovered interest rate parity. As can be seen from the middle panel in the first row, the SOE interest rate reacts strongly positively to a US monetary tightening. However, the increase in the SOE interest rate is less than one for one, such that the spread between the US treasury rate and the treasury rate in the SOE increases. Hence, from standard UIP reasoning one would expect an immediate decline in the exchange rate followed by a subsequent depreciation of the US dollar, and thus an upward sloping response in the upper right panel, the opposite of which actually occurs.

On the other hand, looking at the second row of panels in figure 1 shows that the predictions 
of uncovered interest rate parity are compatible with the responses that follow a SOE monetary policy shock. A monetary shock induced increase in the SOE nominal interest rate (lower middle panel) spurs only a very limited reaction of the US interest rate, and is thus almost equal to an increase in the SOE interest rate relatively to the US interst rate. As the lower right panel shows, this leads to a subsequent depreciation, as the uncovered interest parity proposition suggests.

To summarize, two main results can be taken from this analysis. First, an increase in the US interest rate due to a monetary policy tightening leads to an increase the SOE nominal interest rate, though the connection between US and SOE interest rates is far from perfect. Measured at the peaks of the impulse responses, roughly $50 \%$ of a US interest rate increase is reflected in SOE interest rate increases. Second, and most importantly, we find that exchange rate movements subsequent to US treasury rate changes are inconsistent with standard UIP, whereas there is a response qualitatively in accordance with UIP for the exchange rate response to SOE interest rate changes. We take this asymmetry of exchange rate responses to monetary policy shocks of different origin to be suggestive of a special role of US interest rates and assets. The model presented in the following section is intended to provide an explanation for this asymmetry based on the liquidity value of US treasuries.

\section{The model}

In this section, we derive a modified UIP condition, which allows explaining the exchange rate dynamics presented in the empirical section. For this, we model a liquidity premium on US treasuries, which is - inter alia - affected by the stance of monetary policy. While the focus of the paper is on exchange rate dynamics induced by a modified UIP condition, the determination of the liquidity premium and, in particular, the role of monetary policy requires modelling a full dynamic general equilibrium framework. For simplicity, we abstract from structural relations stemming from international transactions as far as possible and develop a model of the US as a large open economy. The model is based on Reynard and Schabert (2013), who specify the central bank's supply of money as an asset exchange, i.e. an exchange of money against eligible securities. Investors are aware about the fact that only treasury bills are eligible, such that the latter are valued differently from non-eligible assets. To give a preview, the investors' valuation of liquidity and, thus, the liquidity premium on treasuries will vary with the stance of US monetary policy, while they are not affected by foreign shocks.

Households There are infinitely many households $i \in[0,1]$, who are infinitely lived and have identical endowments and identical preferences. They enter period $t$ with holdings of money, $M_{i, t-1} \geq 0$, short-term treasuries, $B_{i, t-1} \geq 0$, and foreign currency denominated bonds $B_{i, t-1}^{*} \geq 0$. Then, they participate in open market operations before they enter the goods market and the asset 
market. ${ }^{8}$ In open market operations money is supplied outright or under repurchase agreements (repos) against eligible securities. We assume that only domestic government bonds are eligible, such that household $i$ faces the following constraint:

$$
I_{i, t} \leq B_{i, t-1} / R_{t}^{m}
$$

where the relative price of money $R_{t}^{m}$ is controlled by the central bank. Households then enter the final goods market, where money is assumed to be the only accepted means of payment. Thus, the household $i^{\prime} s$ goods market expenditures are restricted by the cash constraint

$$
P_{t} c_{i, t} \leq I_{i, t}+M_{i, t-1}
$$

where $P_{t}$ denotes the price level. We assume that consumption $c_{i, t}$ is a bundle of home $c_{i, t}^{h}$ and foreign goods $c_{i, t}^{f}, c_{i . t}=\left(c_{i, t}^{h}\right)^{1-\gamma}\left(c_{i, t}^{f}\right)^{\gamma}$, where $\gamma \geq 0$, such that cost minimizing demand for each good is given by $c_{i, t}^{h}=(1-\gamma) \frac{P_{t}}{P_{t}^{h}} c_{i, t}$ and $c_{i, t}^{f}=\gamma \frac{P_{t}}{S_{t} P_{t}^{f}} c_{i, t}$ and the price index is $P_{t}=$ $\left(P_{t}^{h} /(1-\gamma)\right)^{1-\gamma}\left(S_{t} P_{t}^{f} / \gamma\right)^{\gamma}$.

In the asset market, household $i$ receives payoffs from maturing assets and can reinvest in treasuries, household debt, foreign bonds, and money. Before the asset market opens, it can repurchase treasuries, $B_{i, t}^{R}=R_{t}^{m} M_{i, t}^{R}$. The budget constraint thus reads

$$
\begin{aligned}
& \left(B_{i, t} / R_{t}\right)+M_{i, t}+S_{t}\left(B_{t}^{*} / R_{t}^{*}\right)+\left(R_{t}^{m}-1\right) I_{i, t}+P_{t} c_{i, t}+P_{t} \tau_{t} \\
\leq & B_{i, t-1}+M_{i, t-1}+S_{t} B_{t-1}^{*}+W_{t} n_{i, t}+P_{t} \varphi_{t},
\end{aligned}
$$

where $S_{t}$ denotes the nominal exchange rate, $W_{t}$ the nominal wage rate, $n_{i, t}$ working time, $\tau_{t}$ lumpsum tax, and $\varphi_{t}$ profits from firms. Household $i^{\prime} s$ borrowing is restricted by $M_{i, t} \geq 0, B_{i, t} \geq 0$, and a no-Ponzi game condition in terms of foreign bonds. ${ }^{9}$ Household $i$ maximizes the expected sum of a discounted stream of instantaneous utilities $u$ :

$$
E_{0} \sum_{t=0}^{\infty} \beta^{t} u\left(c_{i, t}, n_{i, t}\right),
$$

where $E_{0}$ is the expectation operator conditional on the time 0 information set, $\beta \in(0,1)$ is the subjective discount factor, and the period utility function is $u\left(c_{i, t}, n_{i, t}\right)=(1-\sigma)^{-1} c_{i, t}^{1-\sigma}-\chi(1+$ $\omega)^{-1} n_{i, t}^{1+\omega}$ with $\sigma, \chi, \omega \geq 0$, subject to (1), (2), (3) and the borrowing constraints, for given initial values $M_{i,-1}, B_{i,-1}$, and $B_{i,-1}^{*}$. The first order conditions for working time, consumption, additional

\footnotetext{
${ }^{8}$ A detailed discussion of the timing of events and the flow of funds can be found in Reynard and Schabert (2013).

${ }^{9}$ Note that in the asset market the central bank reinvests its payoffs from maturing government bonds in newly issued bonds and leaves aggregate money supply unchanged, $\int_{0}^{1} M_{i, t} d i=\int_{0}^{1}\left(M_{i, t-1}+I_{i, t}-M_{i, t}^{R}\right) d i$.
} 
money, as well as for holdings of government bonds, money, and foreign bonds are: $-u_{i, n t} / w_{t}=\lambda_{i, t}$,

$$
\begin{aligned}
u_{i, c t} & =\lambda_{i, t}+\psi_{i, t}, \\
R_{t}^{m}\left(\lambda_{i, t}+\mu_{i, t}\right) & =\lambda_{i, t}+\psi_{i, t}, \\
R_{t} \beta E_{t}\left[\left(\lambda_{i, t+1}+\mu_{i, t+1}\right) \pi_{t+1}^{-1}\right] & =\lambda_{i, t}, \\
\beta E_{t}\left[\left(\lambda_{i, t+1}+\psi_{i, t+1}\right) \pi_{t+1}^{-1}\right] & =\lambda_{i, t}, \\
R_{t}^{*} \beta E_{t}\left[\left(S_{t+1} / S_{t}\right) \lambda_{i, t+1} \pi_{t+1}^{-1}\right] & =\lambda_{i, t},
\end{aligned}
$$

where $\pi_{t}$ denotes the inflation rate $\pi_{t}=P_{t} / P_{t-1}, w_{t}$ the real wage rate $w_{t}=W_{t} / P_{t}$, and $\mu_{i, t}, \psi_{i, t}$, as well as $\lambda_{i, t}$ the multiplier on the collateral constraint (1), the goods market constraint (2), and the asset market constraint (3). Finally, the following complementary slackness conditions hold in the household's optimum $i$.) $0 \leq b_{i, t-1} \pi_{t}^{-1}-R_{t}^{m} i_{i, t}, \eta_{i, t} \geq 0, \eta_{i, t}\left(b_{i, t-1} \pi_{t}^{-1}-R_{t}^{m} i_{i, t}\right)=0$, and ii.) $0 \leq i_{i, t}+m_{i, t-1} \pi_{t}^{-1}-c_{i, t}, \psi_{i, t} \geq 0, \psi_{i, t}\left(i_{i, t}+m_{i, t-1} \pi_{t}^{-1}-c_{i, t}\right)=0$, where $m_{i, t}=M_{i, t} / P_{t}$, $b_{i, t}=B_{i, t} / P_{t}$, and $i_{i, t}=I_{i, t} / P_{t}$, as well as (3) with equality and associated transversality conditions. Relating the first order condition for treasuries (7) to the first order condition for money holdings (8), and using (5) and (6) to substitute out the multipliers, shows that the treasury rate equals the expected policy rate up to first order:

$$
1 / R_{t}=\frac{E_{t}\left[\left(1 / R_{t+1}^{m}\right) \cdot\left(u_{i, c t+1} / \pi_{t+1}\right)\right]}{E_{t}\left(u_{i, c t+1} / \pi_{t+1}\right)}
$$

A comparison of (7) with the first order condition for foreign bonds (9), which are not eligible in open market operations, shows that the long-run (real) treasury rate $R$ can be smaller than the long-run rate of return on foreign bonds $R^{*}$ (for $\lim _{t \rightarrow \infty} S_{t+1} / S_{t}=1$ ), if domestic treasuries exhibit a liquidity value, which is measured by the multiplier $\mu_{t}$ on the collateral constraint (1). We therefore interpret this spreads as a liquidity premium.

Firms The production sector is standard. There is a continuum of monopolistically competitive intermediate producers indexed with $j \in[0,1]$. Intermediate goods are purchased by perfectly competitive bundlers, who bundle/produce the final domestic consumption good $y_{t}$ according to $y_{t}^{\frac{\epsilon-1}{\epsilon}}=\int_{0}^{1} y_{j t}^{\frac{\epsilon-1}{\epsilon}} d j$, leading to a demand $y_{j t}=\left(P_{j t}^{h} / P_{t}^{h}\right)^{-\epsilon} y_{t}$, with $\left(P_{t}^{h}\right)^{1-\epsilon}=\int_{0}^{1}\left(P_{j t}^{h}\right)^{1-\epsilon} d i\left(P_{j t}^{h}\right.$ and $P_{t}^{h}$ being the price of good $j$ and the aggregate price level for domestic goods). Intermediate goods producing firms produce the amount $y_{j t}$ applying the technology $y_{j t}=a_{t} n_{j t}$, where labor productivity $a_{t}$ follows an exogenous first order autoregressive process. Labor demand thus satisfies: $m c_{j t}=w_{t}\left(P_{t} / P_{j t}^{h}\right) / a_{t}$, where $m c$ denotes real marginal costs. Staggered price setting forces a measure $\phi \in[0,1)$ of firms to adjust the previous period price with average inflation, while the measure $1-\phi$ chooses new prices $\bar{P}_{j t}^{h}$ as the solution to $\max _{\bar{P}_{j t}^{h}} E_{t} \sum_{s=0}^{\infty} \phi^{s} q_{t, t+s}\left(\bar{P}_{j t}^{h} y_{j t+s}-P_{t+s}^{h} m c_{t+s} y_{j t+s}\right)$, s.t. $y_{j t+s}=\left(\bar{P}_{j, t}^{h}\right)^{-\epsilon}\left(P_{t+s}^{h}\right)^{\epsilon} y_{t+s}$, where $q_{t, t+s}$ is the stochastic discount factor. The first order condition for their price $\bar{P}_{j t}^{h}$ is given by $Z_{t}=\frac{\epsilon}{\epsilon-1} Z_{1, t} / Z_{2, t}$, where $Z_{t}=\bar{P}_{j t}^{h} / P_{t}^{h}, Z_{1, t}=$ 
$c_{t}^{-\sigma} y_{t} m c_{t}+\phi \beta E_{t}\left(\pi_{t+1}^{H} / \pi^{H}\right)^{\epsilon} Z_{1, t+1}, Z_{1, t}=c_{t}^{-\sigma} y_{t}+\phi \beta E_{t}\left(\pi_{t+1}^{H} / \pi^{H}\right)^{\epsilon-1} Z_{2, t+1}$ and $\pi_{t}^{H}=P_{t}^{h} / P_{t-1}^{h}$. Using the demand constraint, we obtain $1=(1-\phi) Z_{t}{ }^{1-\epsilon}+\phi\left(\pi_{t}^{H} / \pi^{H}\right)^{\epsilon-1}$. Given that aggregate labor input is $n_{t}=\int_{0}^{1} n_{j t} d j$ and $n_{j t}=\left(P_{j t}^{h} / P_{t}^{h}\right)^{-\epsilon} y_{t}$, aggregate domestic output depends on the price dispersion, $y_{t}=a_{t} n_{t} / s_{t}$, where $s_{t} \equiv \int_{0}^{1}\left(P_{j, t}^{h} / P_{t}^{h}\right)^{-\epsilon} d j$ and $s_{t}=(1-\phi) Z_{t}{ }^{-\epsilon}+\phi s_{t-1}\left(\pi_{t}^{H} / \pi^{H}\right)^{\epsilon}$ given $s_{-1}$.

Public sector The government issues short-term nominally risk-free bonds $B_{t}^{T}$, which are either held by domestic households $B_{t}$, foreign households $B_{t}^{F}$, or the central bank $B_{t}^{C}, B_{t}^{T}=B_{t}+B_{t}^{C}+$ $B_{t}^{F}$. We assume that the supply of short-term treasuries is exogenous and we assume that it follows a constant growth rate

$$
B_{t}^{T}=\Gamma B_{t-1}^{T}
$$

where $\Gamma>\beta$. To avoid further effects of fiscal policy, we assume that the government can raise tax revenues in a non-distortionary way, $P_{t} \tau_{t}$, such that the government budget constraint is given by $\left(B_{t}^{T} / R_{t}\right)+P_{t} \tau_{t}^{m}+P_{t} \tau_{t}=B_{t-1}^{T}$, where $P_{t} \tau_{t}^{m}$ denotes central bank transfers.

The central bank supplies money in exchange for treasuries in form of outright sales/purchases $M_{t}$ and repurchase agreements $M_{t}^{R}$. At the beginning of each period, the central bank's stock of treasuries equals $B_{t-1}^{C}$ and the stock of outstanding money equals $M_{t-1}$, it then receives an amount $R_{t}^{m} I_{t}$ of treasuries in exchange for money $I_{t}$, and after repurchase agreements are settled its holdings of treasuries reduces by $B_{t}^{R}$ and the amount of outstanding money by $M_{t}^{R}=B_{t}^{R}$, such that its budget constraint reads $\left(B_{t}^{C} / R_{t}\right)+P_{t} \tau_{t}^{m}=\left(I_{t} / R_{t}^{m}\right)+B_{t-1}^{C}-B_{t}^{R}+M_{t}-M_{t-1}-\left(I_{t}-M_{t}^{R}\right)$. In accordance with central bank practice, we assume that the central bank transfers interest earnings to the government, $P_{t} \tau_{t}^{m}=B_{t}^{C}\left(1-1 / R_{t}\right)+\left(R_{t}^{m}-1\right)\left(M_{t}-M_{t-1}+M_{t}^{R}\right)$, and that it rolls over its maturing assets. Substituting out $P_{t} \tau_{t}^{m}$ and $I_{t}$ with $I_{t}=M_{t}-M_{t-1}+M_{t}^{R}$, in the budget constraint, shows that central bank holdings of treasuries evolve according to $B_{t}^{C}-B_{t-1}^{C}=M_{t}-M_{t-1}$. Further restricting the initial values $B_{-1}^{C}$ and $M_{-1}$ to satisfy $B_{-1}^{C}=-M_{-1}$, we get the central bank balance sheet constraint

$$
B_{t}^{C}=M_{t}
$$

Following large parts of the literature, we assume that the central bank sets the policy rate according to a simple feedback rule

$$
R_{t}^{m}=\left(R_{t-1}^{m}\right)^{\rho}\left(R^{m}\right)^{1-\rho}\left(\pi_{t} / \pi\right)^{\rho_{\pi}(1-\rho)}\left(y_{t} / y\right)^{\rho_{y}(1-\rho)} \exp \left(\varepsilon_{r, t}\right)
$$

where $R^{m}>1, \rho \geq 0, \rho_{\pi} \geq 0$, and $\rho_{y} \geq 0$, and $\varepsilon_{r, t}$ is a normally distributed i.i.d. random variable with $E_{t-1} \varepsilon_{r, t}=0$. The central bank further sets an inflation target, which is consistent with the long-run inflation rate and satisfies $\pi>\beta$. To give a preview, we set the growth rate of T-bills $\Gamma$ equal to the central bank's inflation target, $\Gamma=\pi$, which for the US accords to the estimated growth rate of T-bills (corrected by GDP growth) for the sample period 1966-2007 (see Reynard 
and Schabert, 2013). Finally, the central bank sets the ratio of money supplies under both types of open market operations $\Omega: M_{t}^{R}=\Omega \cdot M_{t}$.

Equilibrium Given that households (firms) behave in an identical way, we will omit individual indices in the subsequent analysis. We assume that foreign households also consume domestically produced goods $c_{t}^{*, h}$, such that market clearing for domestically produced goods demands $y_{t}=$ $c_{t}^{h}+c_{t}^{*, h}$. They further have access to domestic treasuries $\left(B_{t}^{F}\right)$, which implies that aggregate resources of the domestic economy are restricted by $y_{t}=c_{t}-\left(B_{t}^{F} / R_{t}\right)+B_{t-1}^{F}+S_{t}\left(B_{t}^{*} / R_{t}^{*}\right)-S_{t} B_{t-1}^{*}$. As argued by Canzoneri et al. (2013b), foreign households can also assign a positive transaction value to domestic currency, if it serves as a key currency for international trade, like the US dollar. Accordingly, foreign agents hold domestic assets not only as they provide a store of value, but they also value domestic assets for their ability to provide access to domestic currency. In a forex market equilibrium, exchange rate dynamics will therefore be affected by liquidity premia on key currency assets, consistent with (7).

We abstract from further international linkages and assume that the domestic economy is large, in the sense that $\gamma=0$. We view this as an reasonable approximation of the relation between the US economy and small open economies (which we also consider for the empirical analysis). Under this assumption, the model simplifies by $B_{t}^{F}=0, c_{t}^{*, h}=0, y_{t}=c_{t}^{h}, P_{t}=P_{t}^{h}$, and $c_{t}=c_{t}^{h}$, such that all foreign variables except for the foreign interest rate $R_{t}^{*}$ are irrelevant. Accounting for the evidence provided in section 2, we allow for a positive correlation between the foreign interest rate $R_{t}^{*}$ and the domestic treasury rate $R_{t}$. Without attempting to model a full account of international repercussions of US policy decisions, we simply assume an empirically plausible degree of reaction of the foreign interest rate to the domestic treasury rate in specifying

$$
R_{t}^{*}=R^{*} \cdot\left(R_{t} / R\right)^{\kappa} \cdot \varepsilon_{t}^{*}
$$

with $\kappa>0$ and $\varepsilon_{t}^{*}$ being a random mean zero disturbance that depends entirely on foreign factors and $\kappa$ governing the degree of adjustment. The full set of equilibrium conditions for $\gamma=0$ can be found in Appendix A. It should be noted that the model exhibits the classical property of an indetermined level of the exchange rate, which is mainly due to the large open economy assumption. Throughout the subsequent analysis, we will therefore focus on the behavior of the rate of depreciation $E_{t} S_{t+1} / S_{t}$, satisfying (9).

\section{Liquidity premia and exchange rates}

In this section, we show how the existence of a liquidity premium and its response to changes in the domestic monetary policy rate can affect the exchange rate response consistent with the empirical evidence. Throughout the subsequent analysis, we restrict our attention to the case where the goods market constraint, $P_{t} c_{t} \leq M_{t}+M_{t}^{R}$, is binding, such that monetary policy is non-neutral. Combining (5) and (8) leads to $u_{c t}=\beta E_{t}\left(u_{c t+1} / \pi_{t+1}\right)+\psi_{t}$ in equilibrium, which can be written as 
$\psi_{t} / u_{c t}=1-1 / R_{t}^{E u l e r}$, where $R_{t}^{\text {Euler }}$ is defined as $1 / R_{t}^{E u l e r}=\beta E_{t} \frac{u_{c t+1}}{u_{c t} \pi_{t+1}}$ and will be called "Euler equation rate", following Canzoneri et al. (2007). An Euler equation rate larger than one thus indicates a positive valuation for money and implies that households will not hold more money than for consumption expenditures. Then, $\psi_{t}>0$ and the goods market constraint is binding. Now consider the collateral constraint (1), which in equilibrium reads

$$
B_{t-1} / R_{t}^{m} \geq M_{t}-M_{t-1}+M_{t}^{R}
$$

Using (5), (6), and (8), shows that its multiplier $\mu_{t}$ satisfies $\mu_{t} / u_{c t}=\left(1 / R_{t}^{m}\right)-\left(1 / R_{t}^{E u l e r}\right)$ in equilibrium. Hence, when the policy rate is smaller than the Euler rate, $R_{t}^{m}<R_{t}^{E u l e r}$, the multiplier is positive $\mu_{t}>0$ and the collateral constraint (14) is binding. In this case, the goods market constraint is binding as well, $\psi_{t}>0$, given that $R_{t}^{m} \geq 1$. When households get money in exchange for treasuries at a price, $R_{t}^{m}-1$, which is below their marginal valuation of money, $R_{t}^{E u l e r}-1$, they use treasuries to get as much money as until (14) is binding. As a consequence, there exists a premium between treasuries and non-eligible assets which increases with the liquidity value of treasuries $\mu_{t}$. When the policy rate increases, the price of money in terms of treasuries also increases, such that the liquidity value of treasuries falls. For a given value of the Euler equation rate, the liquidity premium is therefore negatively affected by the policy rate.

Combining the first order condition for treasuries (7) with the first order condition for foreign bonds (9), leads to the following arbitrage freeness condition, which relates to a uncovered interest rate parity condition:

$$
\frac{E_{t}\left(\left(S_{t+1} / S_{t}\right)\left(\lambda_{t+1} / \pi_{t+1}\right)\right)}{E_{t}\left(\lambda_{t+1} / \pi_{t+1}\right)}=\frac{R_{t}}{R_{t}^{*}} \cdot \frac{E_{t}\left[\left(1+\mu_{t+1} / \lambda_{t+1}\right)\left(\lambda_{t+1} / \pi_{t+1}\right)\right]}{E_{t}\left(\lambda_{t+1} / \pi_{t+1}\right)},
$$

which can, more compactly, be written as $\Gamma_{t}=\left(R_{t} / R_{t}^{*}\right) \cdot \Lambda_{t}$. According to (15) the term on the RHS, $\Gamma_{t}=\frac{E_{t}\left(\left(S_{t+1} / S_{t}\right)\left(\lambda_{t+1} / \pi_{t+1}\right)\right)}{E_{t}\left(\lambda_{t+1} / \pi_{t+1}\right)}$, which - up to first order - equals the expected rate of depreciation, does not only depend on the spread between the domestic and the foreign interest rate, but is also affected by the liquidity premium $\Lambda_{t}=\frac{E_{t}\left[\left(1+\mu_{t+1} / \lambda_{t+1}\right)\left(\lambda_{t+1} / \pi_{t+1}\right)\right]}{E_{t}\left(\lambda_{t+1} / \pi_{t+1}\right)}$. Given that the latter is negatively related to the domestic policy rate, it tends to counteract the effect of the policy rate on the interest spread (see RHS of 15). For a simplified version of the model, it can be shown that the existence of the liquidity premium leads to substantially different exchange rate dynamics, in particular, when the linkage between domestic and foreign interest rates is large enough (see 13).

Proposition 1 Consider a version of the model under a binding collateral constraint with $\sigma=$ $\Gamma=\pi=1, \Omega \rightarrow \infty$, and $\rho_{\pi}=\rho_{y}=0$. The liquidity premium decreases with the domestic policy rate, $\partial \Lambda_{t} / \partial R_{t}^{m}<0$ if $\rho>0$. Further,

1. an increase in the domestic policy rate leads to an increase in $\Gamma_{t}$ and, up to first order, to an expected future appreciation (depreciation) if $\kappa>1-\rho$ (if $\kappa<1-\rho$ ), and 
2. an increase in the foreign interest rate leads to an increase in $\Gamma_{t}$ and, up to first order, to an expected future appreciation (depreciation).

Proof. See Appendix B.

The results summarized in the proposition show that the existence of the liquidity premium and its endogenous reaction to an increase in the domestic policy rate, can revert the response of expected exchange rate changes. In contrast, a change in the foreign interest rate, which does not alter the liquidity premium on domestic treasuries, leads to a exchange rate response consistent with standard UIP. The condition presented in the part 1. of the proposition further shows that the co-movement between the foreign and the domestic interest rate is also decisive for the exchange rate response. Only if $\kappa$ (see 13) is positive, such that the change in the interest rate spread is less pronounced than the change in the domestic interest rate, the endogenous response of the liquidity premium can lead to a reversal of the exchange rate dynamics. Since the US policy rate is empirically highly persistent, $1-\rho$ is a rather small quantity such that a limited and thus empirically plausible degree of co-movement $\kappa$ suffices to fulfill the condition (see below).

\section{$5 \quad$ Numerical results}

The above proposition showed the model's implications for exchange rate dynamics under the simplifying assumption of an exogenous policy rate as well as for some other special parameter values chosen in order to be able to derive analytical results. Here, we present numerical evidence for a parameterized version of the model that abstains from these simplifications.

For the purposes of this section, we choose model parameters as follows. We specify for the intertemporal substitution elasticity of consumption and for the Frisch elasticity of labor supply $\sigma=\omega=1.5$, which we consider a reasonable trade-off between diverging estimates resulting from microeconomic and macroeconomic data. ${ }^{10}$ We further choose $\chi$ to calibrate working time in the steady state to equal $n=0.33$. The degree of price stickiness is chosen to match typical macro estimates and is set at $\phi=0.75$ (an intermediate value lying between the estimates of Smets and Wouters (2007) and Justiniano and Preston (2010) for the US, which are between 0.65 and 0.90), and the absolute price elasticity is $\epsilon=10$.

The parameters of the Taylor rule are based on Mehra and Minton (2007) to be $\rho_{\pi}=1.5$, $\rho_{y}=0.78$, and persistence $\rho=0.73$, where for simulations we also follow their results in choosing the standard deviation of the innovation to the Taylor rule as 0.326 per cent. We assume that the logarithm of labor productivity follows an $\operatorname{AR}(1)$ process with an autocorrelation coefficient $\rho_{a}$ equal to 0.9 . We set the standard deviation of the innovation to this process, $\varepsilon_{a, t}$, to a value such

\footnotetext{
${ }^{10}$ Card (1994) suggests a range of 0.2 to 0.5 for the Frisch elasticity while Smets and Wouters (2007) estimate $\omega=1.92$. With respect to the intertemporal substitutability of consumption, Barsky et al. (1997) estimate an elasticity of 0.18 using micro data, implying a value of around 5 for $\sigma$. Macroeconomic data generally implies lower estimates, e.g. Smets and Wouters (2007) estimate $\sigma=1.39$.
} 
that the overall standard deviation of simulated output matches the standard value of 1.5 per cent. This requires a standard deviation of $\varepsilon_{a, t}$ of 0.98 per cent. The parameter $\Omega$ is the share of reserves supplied in repurchase operations to total reserves, which we set at $\Omega=1$ (we checked that all results are robust to variations in this value). The steady state inflation rate target $\pi$ (equal to the growth of T-bills $\Gamma$ ) and the long-run policy rate $R^{m}$ are set to the 20 -year averages of U.S. consumer price inflation and, respectively, the Federal Funds rate, $\pi=1.00575$ and $R^{m}=1.0105$.

The discount factor $\beta$ is calibrated to match a steady state liquidity premium of 65 basis points, which follows Canzoneri et al. (2007) who choose this value as the empirical average difference between the interest rate for high-quality (AAA) borrowers and the interest rate on 3 months treasury bills. Thus, the discount factor is set to $\beta=\frac{\pi}{R^{m}+65 \cdot 10^{-4}}=0.9889$. Regarding the foreign interest rate (13), we set $\kappa$ to the ratio of the maximum of the empirical average small economy interest rate response to the maximum of the empirical US policy rate response, which in the empirical estimates presented above in figure 2 is about $0.54 .{ }^{11}$ Foreign interest rate shocks $\varepsilon_{t}^{*}$ are assumed to be serially correlated with an autocorrelation of $\rho$, and their standard deviation is chosen to ensure that the foreign interst rate shows the same volatility as the domestic one.

\subsection{Responses to monetary policy shocks}

We present percentage impulse responses to a one percent shock to the disturbance $\varepsilon_{r, t}$ in the monetary policy rule based on a log-linear approximation of the model. Our focus is on exchange rate dynamics, such that we show the responses of the variables entering the modified interest rate parity condition (15). Thus, figure 2 shows the responses of the interest rate differential $R_{t}-R_{t}^{*}$, the liquidity premium $\Lambda_{t}$, and the expected nominal depreciation rate $E_{t} S_{t+1} / S_{t}$.

As argued above, the empirical results shown in figure 1 point out that typically the foreign interest rate does change positively in response to a shock to US policy rates. This is important in the present context since ignoring this international interest rate linkage would lead us to overstate the consequences of US interest rate shocks on interest rate differentials, which are decisive for exchange rate dynamics in (15), in particular, when, as in our model, endogenous changes in the liquidity premium tend to move the exchange rate in a different direction (see proposition 1 ).

The solid lines in figure 2 show that after a US monetary policy shock that raises the policy interest rate $R_{t}^{m}$, the bond rate $R_{t}$ rises, too, and thus there is an increase in the international interest rate differential $R_{t}-R_{t}^{*}$. The liquidity premium declines, as described in section 2 . From the modified interest rate parity condition (15), all else equal, the increase in the interest rate differential would tend to lead to a future depreciation, while the decrease in the liquidity premium would lower it. Since the international interest rate connection is set at an empirically plausible value $(\kappa=0.54)$, the interest rate differential responds less strongly to a contractionary

\footnotetext{
${ }^{11}$ Note that this does not accomodate any humps in the responses, which are present empirically but not replicated by the model.
} 

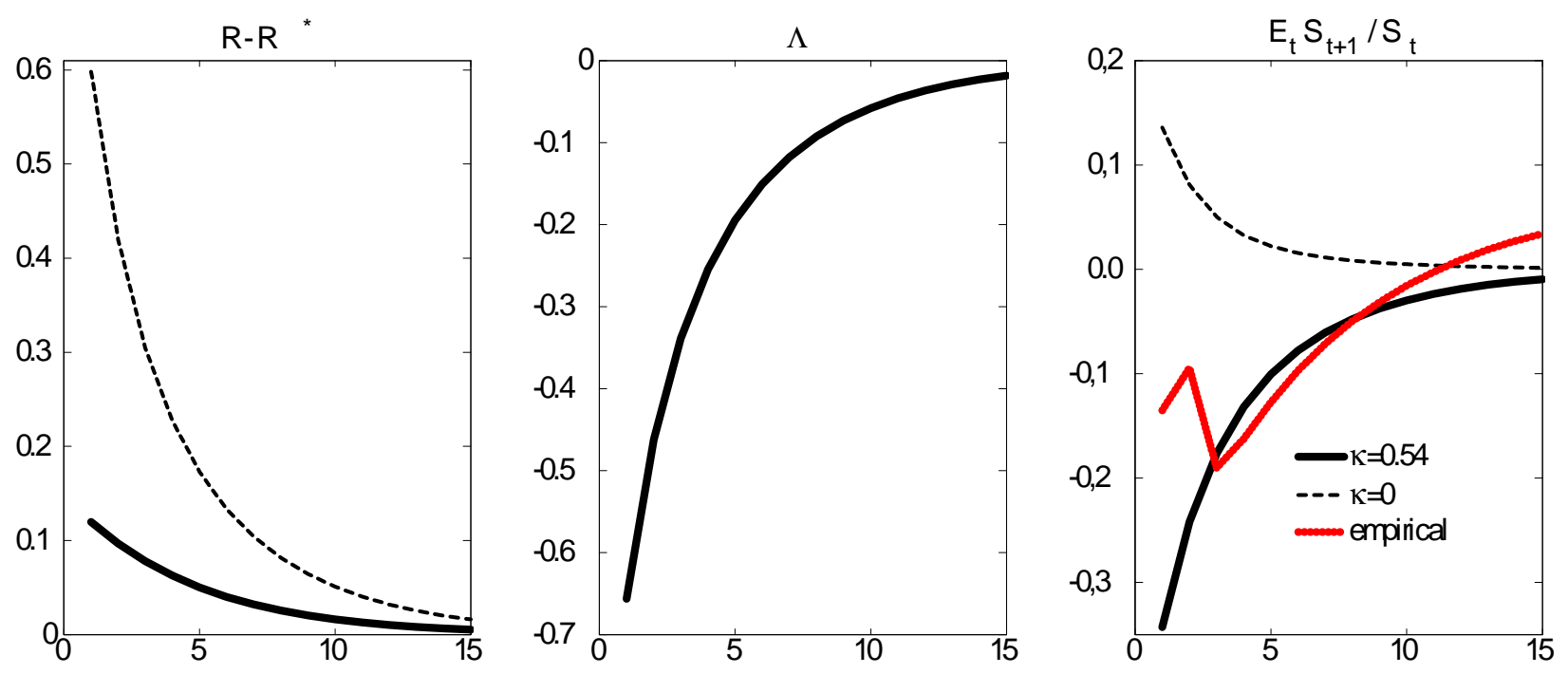

Figure 2: Responses to one percentage point increase in domestic policy interest rate shock

US monetary shock, and the same amount of decrease in the liquidity premium leads to an expected exchange rate appreciation (a negative response of $E_{t} S_{t+1} / S_{t}$ ). In this way, the model is able to explain the negative relation between the interest rate differential and the depreciation rate that is observed in the data.

For comparison, the dashed lines show the impulse responses for $\kappa=0$, which is the case of no international interest rate linkage. In this case, the domestic monetary policy induced interest rate shock translates into a much stronger interest rate differential. Since the response of the liquidity premium is necessarily the same as before, it turns out that the effect working through the interest rate differential dominates for this parameterization, such that the model implies a counterfactual increase in the depreciation rate. In this case, the existence of the liquidity premium modifies the result quantitatively, but does not imply a qualitative departure from UIP.

In the rightmost panel, the red dotted line is the corresponding empirical estimate of the depreciation rate following a US interest rate shock for comparison (recall that in the VAR we used above, as common in the empirical literature, the nominal (log) exchange rate entered as a variable, whereas in the theoretical discussion here we focus on the slope of the exchange rate response, namely the rate of depreciation. In the figure, the red line represents the depreciation rate that is implicit in our empirically estimated log exchange rate response, obtained by converting the empirical response as shown in figure 1 to its quarterly equivalent and then taking the forward difference). The overall pattern of the empirical (red) response of the depreciation rate is in line with the one in our preferred specification (solid black). Although we emphasize that the model as it stands is deliberately stylized and not suited to closely match the properties of data, its predictions are nonetheless in qualitative accordance with empirical observation. 

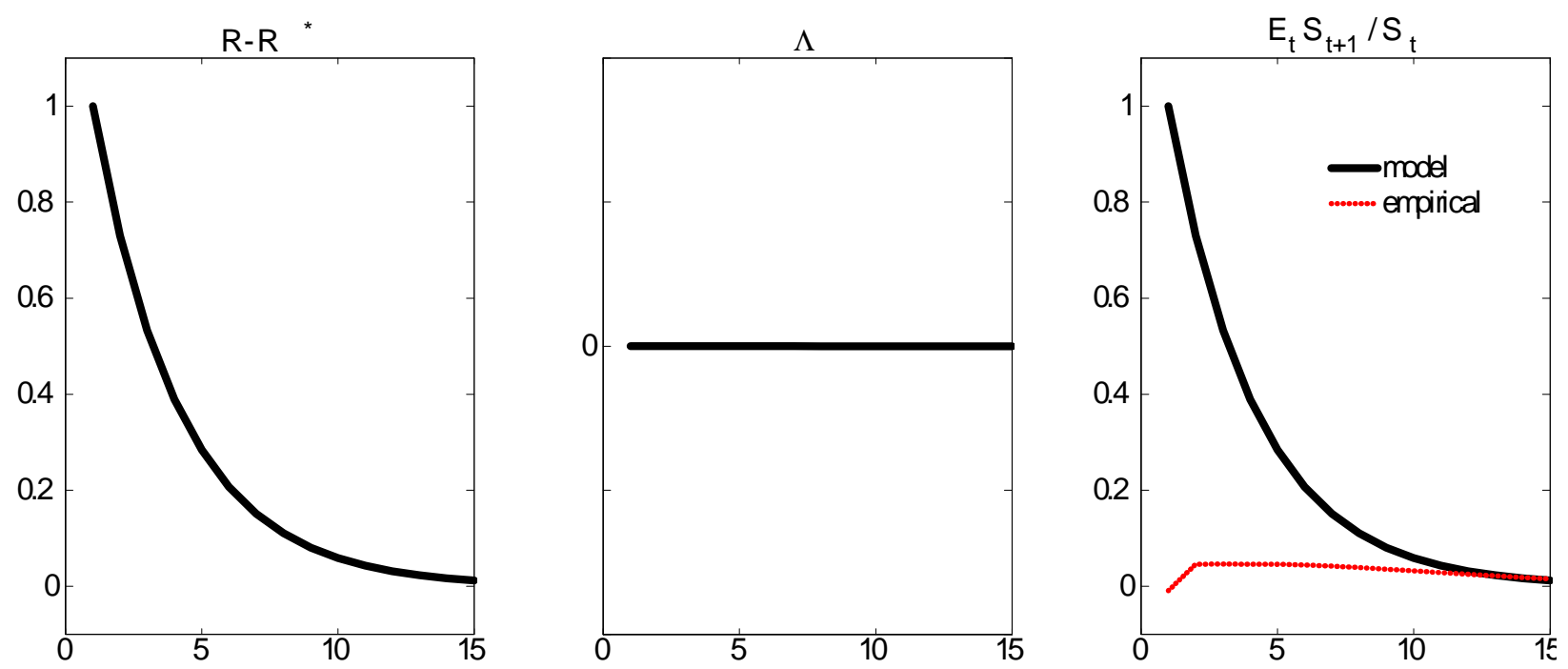

Figure 3: Responses to one percentage point increase in foreign (SOE) policy interest rate shock

Figure 3 shows the response to a negative autocorrelated shock to the foreign (SOE) interest rate innovation $\varepsilon_{t}^{*}$. Approximating the observed weak response of the US interest rate to a SOE interest rate shock (see figure 1), our model implies that the domestic (i.e. US) interest rate does not respond. By construction, since it is assumed that the domestic economy is large, the foreign interest rate shock does not affect domestic variables and the liquidity premium does not change. Hence, the result as shown in the rightmost panel can be seen to be the standard UIP prediction, namely a positive association between the interest rate differential (here brought about by a decrease in the foreign interest rate $R_{t}^{*}$ ) and the depreciation rate. The sign of the response of the depreciation rate is consistent with what we observed in the VAR analysis (see red line), whereas the magnitude of the response is clearly overstated, a property that our model shares with all models that imply a standard UIP condition.

\subsection{Unconditional correlations}

So far we have looked at the response of the depreciation rate to interest rate innovations induced by monetary policy shocks. The purpose was to demonstrate that the model with liquidity premia is able to account for the empirical evidence on the exchange rate effects of monetary policy shocks, as exemplified by the results in section 2 above. However, the empirical literature has shown that the UIP prediction fails not only conditional on monetary policy shocks, but also unconditionally. This is evidenced in the kind of empirical tests conducted by Fama (1984) and many others surveyed in Froot and Thaler (1992) and Engel (2013). The negative association between interest rate differentials and depreciation rates seems to hold in general. In this section, we therefore look beyond responses to monetary policy shocks, and present the limitations of our model when 
facing the challenge to produce an unconditional association between interest rate differentials and expected depreciation as found in the data. We do so by stochastically simulating the model and then performing regressions with the artificial data. The simulations assume normally distributed domestic interest rate shocks, foreign interest rate shocks, and technology shocks with autoregressive properties and variances as described above. We generate artificial time series of length 500, and the results presented below are based on averages of 1000 runs.

The empirical literature on UIP typically uses a regression of the following type (see e.g. the survey by Froot and Thaler, 1992),

$$
E_{t} \widehat{S}_{t+1}-\widehat{S}_{t}=\delta_{0}+\delta\left(\widehat{R}_{t}-\widehat{R}_{t}^{*}\right)+\eta_{t}
$$

where $\delta_{0}$ and $\delta$ are parameters to be estimated, $\eta_{t}$ is stochastic disturbance term, and carets denote loglinearized terms. To connect this to the discussion of our model, note that log-linearizing the modified interest rate parity condition (15) and rearranging we arrive at

$$
E_{t} \widehat{S}_{t+1}-\widehat{S}_{t}=\widehat{R}_{t}-\widehat{R}_{t}^{*}+\widehat{\Lambda}_{t}
$$

The standard test of UIP in the empirical literature is to run the regression (16) on empirical data and test the hypothesis that $\delta_{0}=0$ and $\delta=1$. By looking at the theoretical expression in (17), one sees that this hypothesis is true if the liquidity premium is zero. Otherwise, if our model is true and the liquidity premium is non-negligible, the standard UIP regression suffers from omitted variable bias. Our question in this section is whether omitting the (empirically unobservable) premium in estimated UIP regressions can explain their reported empirical test results. It is well known that econometric estimates of (16) typically find coefficient values of $\delta$ notably smaller than one, and often even negative.

Here, we assess what an econometrician would find in a world characterized by our model. For the regressions, we use the realized depreciation rate $\widehat{S}_{t}-\widehat{S}_{t-1}$ from the model simulations and regress it on the model interest rate differential $\widehat{R}_{t-1}-\widehat{R}_{t-1}^{*}$, since this is the data that an econometrician not observing expectations would have to work with in empirical work with real world data. However, we emphasize that the results would change only very little if we took the model's true expected depreciation rate $E_{t} \widehat{S}_{t+1}-\widehat{S}_{t}$ and regressed it on $\widehat{R}_{t}-\widehat{R}_{t}^{*}$, instead.

Using this procedure, we get an average (over 1000 simulation runs) regression coefficient $\delta$ of 0.4370 with an average standard error of 0.0451 . Recall that if we ran the same simulations in a model without liquidity premia, the estimated coefficient would be centered on 1 , the value predicted by the standard UIP relation. In the present model where liquidity premia are present, the estimated coefficients are statistically significantly smaller than 1 due to the influence of the omitted liquidity premium variable. However, the empirical literature often finds negative coefficients (Froot and Thaler, 1992, report a mean estimate for $\delta$ of -0.8 over various studies), which 
cannot be replicated by the model. The reason is that we also assume that there are shocks to the foreign interest rate. Since there is no liquidity premium associated with foreign assets, these foreign interest rate shocks entail a partial effect that is consistent with UIP, and would thus (when taken in isolation) produce a $\delta$ coefficient of 1 . The overall regression coefficient that we estimate then reflects the combined effects of the modified UIP relation in the case of domestic monetary policy and productivity shocks and standard UIP dynamics in case of foreign interest rate shocks. To see this more clearly, we repeated the simulations setting the volatility of foreign interest rate shocks to zero. The estimated average coefficient $\delta$ in this case is -1.2360 with an average standard error of 0.0273 . Thus, in this scenario the model replicates the finding of a strongly negative slope coefficient as found in much of the empirical literature. Thus, to explain the unconditional correlation one would have to assume that US monetary policy and technology shocks account for the largest part of the variance of exchange rates.

\section{Conclusion}

This paper examines the role of liquidity premia for exchange rate dynamics. We apply a macroeconomic approach to liquidity premia on short-term treasuries originating from monetary policy implementation. The liquidity premium leads to a modification of uncovered interest rate parity (UIP), which contributes to explaining observed deviations from the latter. Specifically, the endogenous reaction of the liquidity premium to interest rate changes can lead to a future appreciation when the domestic interest rate is relatively high.

We provide empirical evidence that this pattern is particularly relevant for changes in interest rates on US treasuries, which are known to provide transaction services, both nationally and internationally. In contrast, our panel VAR analysis shows that changes in the interest rate of a small open economy leads to exchange rate responses that are consistent with UIP predictions. The liquidity premia approach presented in this paper thus helps to understand exchange rate responses to monetary policy shocks. However, since these arguably account for a limited fraction of the total variance of exchange rates, our theory does not provide a solution for the forward premium puzzle. 


\section{$7 \quad$ References}

Atkeson, A., and P.J. Kehoe, 2009, On the Need for a New Approach to Analyzing Monetary Policy, NBER Macroeconomics Annual 2008 23, 389-425.

Bansal, R., and W.J. Coleman II., 1996, A Monetary Explanation of the Equity Premium, Term Premium, and Risk-Free Rate Puzzle, Journal of Political Economy 104, 1135-1171.

Bjornland, H.C., 2009, Monetary Policy and Exchange Rate Overshooting: Dornbusch Was Right After All, Journal of International Economics 79, 64-77.

Canzoneri M.B., R. E. Cumby, and B.T. Diba, 2007, Euler Equations and Money Market Interest Rates: A Challenge for Monetary Policy Models, Journal of Monetary Economics $54,1863-1881$.

Canzoneri M.B., R. E. Cumby, B.T. Diba, and D. Lopez-Salido, 2008, Monetary Aggregates and Liquidity in a Neo-Wicksellian Framework, Journal of Money, Credit and Banking 40, 1667-1698.

Canzoneri M.B., R. E. Cumby, B.T. Diba, and D. Lopez-Salido, 2013a, Key Currency Status: An Exorbitant Privilege and an Extraordinary Risk, Journal of International Money and Finance 37, 371-393.

Canzoneri M.B., R. E. Cumby, and B.T. Diba, 2013b, Addressing International Empirical Puzzles: the Liquidity of Bonds, Open Economies Review 24, 197-215.

Eichenbaum, M. and C.L. Evans, 1995, Some Empirical Evidence on the Effects of Shocks to Monetary Policy on Exchange Rates, Quarterly Journal of Economics 110, 975-1009.

Engel, C., 2012, The Real Exchange Rate, Real Interest Rates, and the Risk Premium, unpublished manuscript, University of Wisconsin.

Engel, C., 2013, Exchange Rates and Interest Parity, Handbook of International Economics vol. 4, eds. G. Gopinath, E. Helpman, and K. Rogoff, forthcoming.

Fama, E.F. 1984, Forward and Spot Exchange Rates, Journal of Monetary Economics 14, 319-38.

Froot,K.A. and R.H. Thaler, 1990, Anomalies: Foreign Exchange, Journal of Economic Perspectives 4, 179-192.

Hoermann, M. and A. Schabert, 2012, Monetary Policy, Key Currency and Exchange Rate Dynamics, unpublished manuscript, University of Cologne.

Justiniano, A. and B. Preston, 2010, Can Structural Small Open Economy Models Account for the Influence of Foreign Shocks?, Journal of International Economics 81, 61-74. 
Krishnamurthy, A., Vissing-Jorgensen, A., 2012, The Aggregate Demand for Treasury Debt, Journal of Political Economy 120, 233-267.

Linnemann, L. and A. Schabert, 2010, Debt Non-neutrality- Policy Interactions, and Macroeconomic Stability, International Economic Review 51, 461-474.

Longstaff, F., 2004, The Flight-To-Liquidity Premium in U.S. Treasury Bond Prices, Journal of Business 77, 511-526.

Mehra, Y.P. and B.D. Minton, 2007, A Taylor Rule and the Greenspan Era, Federal Reserve Bank of Richmond Economic Quarterly 93, 229-250.

Ravn, M., S. Schmitt-Grohe and M. Uribe, 2012, Consumption, Government Spending, and the Real Exchange Rate, Journal of Monetary Economics 59, 215-234.

Nickell, S., 1981, Biases in Dynamic Models with Fixed Effects, Econometrica 49, 1417-1426.

Reynard, S. and A. Schabert, 2013, Monetary Policy, Interest Rates, and Liquidity Premia, unpublished manuscript, University of Cologne.

Scholl, A. and H. Uhlig, 2008, New evidence on the puzzles: Results from agnostic identification on monetary policy and exchange rates, Journal of International Economics, 1-13.

Smets, F., and R. Wouters, 2007, Shocks and Frictions in U.S. Business Cycles: A Bayesian DSGE approach. American Economic Review 97, 586-606. 


\section{Appendix}

\section{A Equilibrium conditions for the large open economy}

In equilibrium, aggregate asset holdings satisfy $B_{t}^{(*)}=\int B_{i, t}^{(*)} d i, M_{t}^{R}=\int_{0}^{1} M_{i, t}^{R} d i, M_{t}=\int_{0}^{1} M_{i, t} d i$, $\int I_{i, t} d i=I_{t}=M_{t}-M_{t-1}+M_{t}^{R}$, and $B_{t}^{T}=B_{t}+B_{t}^{C}$. Assuming that the domestic economy is large, $\gamma=0$ and $B_{t}^{F}=0$, implies that $c_{t}^{*, h}=0, y_{t}=c_{t}^{h}, P_{t}=P_{t}^{h}$ and $c_{t}=c_{t}^{h}$ hold. We can then summarize the rational expectations equilibrium (REE) as a set of sequences for $\left\{c_{t}, n_{t}, w_{t}, m_{t}\right.$, $\left.m_{t}^{R}, b_{t}, b_{t}^{T}, Z_{t}^{1}, Z_{t}^{2}, \pi_{t}, s_{t}, R_{t}^{*}, R_{t}, R_{t}^{m}, R_{t}^{E u l e r}, \mu_{t}, \lambda_{t}, E_{t} \frac{S_{t+1}}{S_{t}}\right\}$ satisfying

$$
\begin{aligned}
& \chi n_{t}^{\omega} / w_{t}=\lambda_{t}, \\
& \frac{\chi n_{t}^{\omega}}{w_{t}}=\beta E_{t} \frac{c_{t+1}^{-\sigma}}{\pi_{t+1}}, \\
& E_{t} \frac{c_{t+1}^{-\sigma}}{\pi_{t+1}}=R_{t} E_{t} \frac{c_{t+1}^{-\sigma}}{\pi_{t+1} R_{t+1}^{m}}, \\
& 1 / R_{t}^{\text {Euler }}=\beta E_{t}\left[c_{t+1}^{-\sigma} /\left(c_{t}^{-\sigma} \pi_{t+1}\right)\right], \\
& c_{t}=m_{t}+m_{t}^{R} \text {, for } R_{t}^{\text {Euler }}>1 \text {, or } c_{t} \leq m_{t}+m_{t}^{R} \text {, for } R_{t}^{\text {Euler }}=1 \\
& m_{t}+m_{t}^{R}=\frac{m_{t-1}}{\pi_{t}}+\frac{b_{t-1} / \pi_{t}}{R_{t}^{m}} \text {, for } \mu_{t}>0 \text {, } \\
& \text { or } m_{t}+m_{t}^{R} \leq \frac{m_{t-1}}{\pi_{t}}+\frac{b_{t-1} / \pi_{t}}{R_{t}^{m}} \text {, for } \mu_{t}=0 \text {, } \\
& m_{t}^{R}=\Omega m_{t}, \\
& b_{t}=b_{t}^{T}-m_{t}, \\
& b_{t}^{T}=\Gamma b_{t-1}^{T} / \pi_{t}, \\
& \mu_{t} / \lambda_{t}=\left(R_{t}^{\text {Euler }} / R_{t}^{m}\right)-1, \\
& E_{t}\left[\frac{\lambda_{t+1}+\mu_{t+1}}{\lambda_{t}} \frac{R_{t}}{\pi_{t+1}}\right]=E_{t}\left[\frac{S_{t+1}}{S_{t}} \frac{\lambda_{t+1}}{\lambda_{t}} \frac{R_{t}^{*}}{\pi_{t+1}}\right] \text {, } \\
& Z_{t}^{1}=[\epsilon /(\epsilon-1)] c_{t}^{-\sigma} y_{t}\left(w_{t} / a_{t}\right)+\phi \beta \pi^{-\epsilon} E_{t} \pi_{t+1}^{\epsilon} Z_{t+1}^{1}, \\
& Z_{t}^{2}=c_{t}^{-\sigma} y_{t}+\phi \beta \pi^{1-\epsilon} E_{t} \pi_{t+1}^{\epsilon-1} Z_{t+1}^{2} \text {, } \\
& 1=(1-\phi)\left(Z_{t}^{1} / Z_{t}^{2}\right)^{1-\varepsilon}+\phi \pi^{1-\epsilon} \pi_{t}^{\epsilon-1}, \\
& y_{t}=c_{t}, \\
& y_{t}=a_{t} n_{t} / s_{t}, \\
& s_{t}=(1-\phi)\left(Z_{t}^{1} / Z_{t}^{2}\right)^{-\epsilon}+\phi \pi^{-\epsilon} s_{t-1} \pi_{t}^{\epsilon} \text {, } \\
& R_{t}^{m}=\left(R^{m}\right)^{1-\rho}\left(R_{t-1}^{m}\right)^{\rho}\left(\pi_{t} / \pi\right)^{\rho_{\pi}(1-\rho)}\left(y_{t} / y\right)^{\rho_{y}(1-\rho)} \exp \left(\varepsilon_{r, t}\right) \text {, } \\
& R_{t}^{*}=R^{*}\left(R_{t} / R\right)^{\kappa} \exp \left(\varepsilon_{t}^{*}\right),
\end{aligned}
$$

and the transversality conditions, a monetary policy setting $\left\{R_{t}^{m} \geq 1\right\}_{t=0}^{\infty}$ according to (12), $\Omega_{t}>0$, and $\pi \geq \beta$, and a fiscal policy setting $\Gamma \geq 1$, for given sequences of stochastic variables $\left\{a_{t}, \varepsilon_{r, t}, \varepsilon_{t}^{*}\right\}_{t=0}^{\infty}$, and initial values $M_{-1}^{H}>0, B_{-1}>0, B_{-1}^{T}>0$, and $s_{-1} \geq 1$. 


\section{B Appendix to section 4}

Suppose that the average policy rate and the inflation target satisfy $R^{m}<\pi / \beta$ and $\pi>\beta \Rightarrow$ $R^{\text {Euler }}>1$, where variables without time index denote steady state values. Then, the collateral constraint (14) as well as the cash constraint (2) are binding in the steady state, given that their multiplier are strictly positive, $\mu=c^{-\sigma}\left[\left(1 / R^{m}\right)-\beta / \pi\right]>0$ and $\psi=c^{-\sigma}[1-\beta / \pi]>0$. For the parameter values $\sigma=\Gamma=\pi=1$, and $\Omega \rightarrow \infty$, a REE in a neighborhood of this steady state reduces a to set of sequences $\left\{c_{t}, n_{t}, w_{t}, m_{t}^{R}, b_{t}, m c_{t}, Z_{t}^{1}, Z_{t}^{2}, \pi_{t}, s_{t}, R_{t}^{*}, R_{t}, R_{t}^{m}, \mu_{t}, \lambda_{t}, E_{t} \frac{S_{t+1}}{S_{t}}\right\}_{t=0}^{\infty}$ and $P_{0}>0$ satisfying (27)-(36), $\chi n_{t}^{\omega}=c_{t}^{-1} w_{t} / R_{t}^{\text {Euler }}$,

$$
\begin{aligned}
\lambda_{t} & =\beta E_{t}\left[c_{t+1}^{-1} / \pi_{t+1}\right], \\
1 / R_{t}^{\text {Euler }} & =\beta E_{t}\left[c_{t+1}^{-1} /\left(c_{t}^{-1} \pi_{t+1}\right)\right], \\
E_{t} \frac{c_{t+1}^{-1}}{\pi_{t+1}} & =R_{t} E_{t} \frac{c_{t+1}^{-1}}{\pi_{t+1} R_{t+1}^{m}}, \\
c_{t} & =m_{t}^{R}, \\
m_{t}^{R} & =\frac{b_{t-1} / \pi_{t}}{R_{t}^{m}}, \\
b_{t} & =b_{t-1} / \pi_{t},
\end{aligned}
$$

and the transversality conditions, a monetary policy setting $\left\{R_{t}^{m} \geq 1\right\}_{t=0}^{\infty}$ according to (12), for given sequences of stochastic variables $\left\{a_{t}, \varepsilon_{r, t}, \varepsilon_{t}^{*}\right\}_{t=0}^{\infty}$, and initial values $B_{-1}>0, B_{-1}^{T}>0$, and $s_{-1} \geq 1$.

Proof of proposition 1. Consider the modified UIP condition (15), which can be written as

$$
\Gamma_{t}=\left(R_{t} / R_{t}^{*}\right) \cdot \Lambda_{t}
$$

where $\Lambda_{t}=\frac{E_{t}\left[\left(1+\mu_{t+1} / \lambda_{t+1}\right)\left(\lambda_{t+1} / \pi_{t+1}\right)\right]}{E_{t}\left(\lambda_{t+1} / \pi_{t+1}\right)}$ and $\Gamma_{t}=\frac{E_{t}\left(\left(S_{t+1} / S_{t}\right)\left(\lambda_{t+1} / \pi_{t+1}\right)\right)}{E_{t}\left(\lambda_{t+1} / \pi_{t+1}\right)}$. Combining (40) and (41) to $c_{t}=b_{t-1} /\left(R_{t}^{m} \pi_{t}\right)$ as well as (37) and (38) to $c_{t} \lambda_{t}=1 / R_{t}^{\text {Euler }}$, gives $\lambda_{t}=\pi_{t}\left(R_{t}^{m} / R_{t}^{\text {Euler }}\right) / b_{t-1}$. Using the latter and (27) to substitute out the multipliers $\lambda_{t+1}$ and $\mu_{t+1}$, the terms $\Gamma_{t}$ and $\Lambda_{t}$ in (43) can be written as

$$
\Lambda_{t}=\frac{1}{E_{t}\left(R_{t+1}^{m} / R_{t+1}^{\text {Euler }}\right)} \quad \text { and } \quad \Gamma_{t}=\frac{E_{t}\left(\left(S_{t+1} / S_{t}\right)\left(R_{t+1}^{m} / R_{t+1}^{\text {Euler }}\right)\right)}{E_{t}\left(R_{t+1}^{m} / R_{t+1}^{\text {Euler }}\right)} .
$$

Replacing consumption in (38) with $c_{t}=b_{t-1} /\left(R_{t}^{m} \pi_{t}\right)$, and substituting out $b_{t}$ with (42), leads to $R_{t}^{m} / R_{t}^{\text {Euler }}=\beta E_{t} R_{t+1}^{m}$. Given that monetary policy satisfies $\rho_{\pi}=\rho_{y}=0$, such that (35) simplifies to $R_{t}^{m}=\left(R^{m}\right)^{1-\rho}\left(R_{t-1}^{m}\right)^{\rho} \exp \left(\varepsilon_{r, t}\right)$, the ratio $R_{t}^{m} / R_{t}^{\text {Euler }}$ satisfies

$$
R_{t}^{m} / R_{t}^{\text {Euler }}=\left(R_{t}^{m}\right)^{\rho} \cdot \beta\left(R^{m}\right)^{(1-\rho)} \exp \left[(1 / 2) \operatorname{var}\left(\varepsilon_{r, t}\right)\right] .
$$

where we used that $E_{t} \exp \left(\varepsilon_{t+1}\right)^{x}=\exp \left[(1 / 2)\left(x^{2}\right) \operatorname{var}\left(\varepsilon_{r, t}\right)\right]$. Hence, the terms in (44) can be 
simplified to

$$
\begin{aligned}
& \Lambda_{t}=\left(1 / R_{t}^{m}\right)^{\rho^{2}} \cdot \Phi_{1}, \\
& \Gamma_{t}=E_{t}\left(S_{t+1} / S_{t}\right)+\operatorname{cov}_{t}\left(S_{t+1} / S_{t}, \exp \left(\varepsilon_{r, t+1}\right)^{\rho}\right) \exp \left[-\rho^{2}(1 / 2) \operatorname{var}\left(\varepsilon_{r, t}\right)\right],
\end{aligned}
$$

where $\Phi_{1}=\left(R^{m}\right)^{-(1+\rho)(1-\rho)}(1 / \beta) \exp \left[-\left(1+\rho^{2}\right)(1 / 2) \operatorname{var}\left(\varepsilon_{r, t}\right)\right]$ is constant. Thus, (46) implies that $\Lambda_{t}$ is strictly decreasing in the policy rate if $\rho>0$, which establishes the first claim in the proposition.

Using (13), to substitute out the foreign rate $R_{t}^{*}$ in (43), leads to $\Gamma_{t}=R_{t}^{1-\kappa}\left[\left(R^{*} / R^{\kappa}\right) \varepsilon_{t}^{*}\right]^{-1} \Lambda_{t}$. Now use the arbitrage freeness condition (10) and substitute out $c_{t+1}^{-1}$ with $c_{t+1}^{-1}=\lambda_{t+1} R_{t+1}^{E u l e r}$ and $\lambda_{t+1} / \pi_{t+1}$ with $\lambda_{t+1} / \pi_{t+1}=\left(R_{t+1}^{m} / R_{t+1}^{\text {Euler }}\right) / b_{t}$, leading to $R_{t}=E_{t} R_{t+1}^{m}$ and - by using the policy rule (35) - to $R_{t}=E_{t}\left[\left(R_{t}^{m}\right)^{\rho}\left(R^{m}\right)^{1-\rho} \exp \left(\varepsilon_{r, t+1}\right)\right]$, which can be used to write the RHS of (43) in terms of the current policy rate $R_{t}^{m}$,

$$
\Gamma_{t}=\left[\left(R_{t}^{m}\right)^{\rho} E_{t}\left[\exp \left(\varepsilon_{r, t+1}\right)\right]\left(R^{m}\right)^{1-\rho}\right]^{1-\kappa}\left[\left(R^{*} / R^{\kappa}\right) \varepsilon_{t}^{*}\right]^{-1} \cdot \Lambda_{t}
$$

Applying the expressions of $\Lambda_{t}$ and $\Gamma_{t}$ in (46) and (47), we get

$$
E_{t}\left(S_{t+1} / S_{t}\right)+\Theta_{t}=\left(R_{t}^{m}\right)^{-\rho(\kappa-(1-\rho))}\left(1 / \varepsilon_{t}^{*}\right) \cdot \Phi_{2},
$$

where $\Phi_{2}=\left(R^{*} / R^{\kappa}\right)(1 / \beta)\left(R^{m}\right)^{(\rho-1)(\kappa+\rho)} \exp \left[-\left(\rho^{2}+\kappa\right)(1 / 2) \operatorname{var}\left(\varepsilon_{r, t}\right)\right]$ is constant and the term $\Theta_{t}$ depends on a potentially time varying second order term, $\Theta_{t}=\operatorname{cov}_{t}\left(S_{t+1} / S_{t}, \exp \left(\varepsilon_{r, t+1}\right)^{\rho}\right)$. $\exp \left[-\rho^{2}(1 / 2) \operatorname{var}\left(\varepsilon_{r, t}\right)\right]$. Hence, (48) implies that if $\kappa>1-\rho(\kappa<1-\rho)$ an increase in the domestic policy rate leads to an appreciation (a depreciation) up to first order. An increase in the foreign interest rate, which is induced by a increase in $\varepsilon_{t}^{*}$, is as well, up to first order, associated with an subsequent appreciation of the domestic currency. 

